\title{
Clinical use of estimating glomerular filtration rate equ- ations during pregnancy
}

\author{
Luiz Paulo José Marques ${ }^{1^{*}}$, Regina Rocco ${ }^{2}$, Maria Helena Victor ${ }^{1}$, \\ Benedita Calheiros de Novaes ${ }^{2}$, Ana Luiza Batista de Carvalho ${ }^{1}$, Omar da Rosa Santos ${ }^{1}$
}

\footnotetext{
${ }^{1}$ Renal Unit of Gaffrèe and Guinle University Hospital-Department of Medicine, Federal University of Rio de Janeiro State, Rio de Janeiro, Brazil; marqueslpj@iG.com.br

${ }^{2}$ Obstetric Unit of Gaffrèe and Guinle University Hospital-Department of Medicine, Federal University of Rio de Janeiro State, Rio de Janeiro, Brazil
}

Received3 November 2010; revised 5 November 2010; accepted 8 November 2010.

\section{ABSTRACT}

Background: Kidney disease, even when mild, was once considered so major an impediment to successful pregnancy and so dangerous to the mother's wellbeing. High-risk pregnancy mainly associated to renal impairment may occur in $10-20 \%$ of gestations and it is very important that renal function is closely monitored to prevent or minimize maternal and fetal complications. This study was designed to investigate the performance of Cockcroft-Gault $\mathbf{C G}_{\mathrm{eq}}$ and the simplified MDRD $_{\text {eq }}$ equations in healthy pregnant women to assess renal function. Methods: We studied 167 normal ambulatory pregnant women and kidney function was contemporaneously estimated through the $\mathbf{C G}_{\mathrm{eq}}$ and the simplified $M{ }^{2} D_{\text {eq }}$ and calculated through the creatinine clearance $\left(\mathrm{C}_{\mathrm{cr}}\right)$. Serum and urinary creatinine were assayed using Jaffé reaction method in the same AutoAnalyser. Results: When we compared calculated and estimated clearences for measurement of kidney function we observed that $\mathbf{C G}_{\mathrm{eq}}$ overestimated renal function $\left(\mathrm{CG}_{\mathrm{eq}}=168.41 \pm 38.80 \mathrm{ml} /\right.$ $\min / 1.73 \mathrm{~m}^{2}, \mathrm{C}_{\mathrm{cr}}=146.27 \pm 30.49 \mathrm{ml} / \mathrm{min} / 1.73 \mathrm{~m}^{2}$, $\mathrm{p}<0.001), M^{2} D_{\text {eq }}$ underestimated renal function $\left(C_{\mathrm{cr}}=146.27 \pm 30.49 \mathrm{ml} / \mathrm{min} / 1.73 \mathrm{~m}^{2}\right.$, MDRD $_{\text {eq }}=129.15 \pm 29.28 \mathrm{ml} / \mathrm{min} / 1.73 \mathrm{~m}^{2}, \mathrm{p}<$ 0.001). Conclusions: Our results demonstrated that $\mathbf{C G}_{\mathrm{eq}}$ overestimated, $M \mathrm{MRD}_{\mathrm{eq}}$ underestimated significantly kidney function during gestation in healthy women and cannot be recommended to assess renal function in obstetric practice. $C_{c r}$ remains a useful clinical tool in pregnant women until the development of a specific equation that considers the several important maternal renal physiological alterations and provides the measure of GFR the most unbiased and precise as possible.

Keywords: Pregnancy, Kidney function, Glomerular Filtration Rate, MDRD equation, Cockcroft-Gault equation.

\section{INTRODUCTION}

The pregnancy promotes several important changes in renal hemodynamics. There are increases in cardiac output and plasma volume that appear to parallel those of Glomerular filtration rate (GFR) and Renal Plasma Flow (RPF), but vascular resistance and blood pressure fall at the same time [1]. Maternal renal adaptation is characterized markedly increase in GFR, approximately $50 \%$ greater than pre-pregnant value [2]. High-risk pregnancies, mainly associated to renal impairment, may occur in $10-20 \%$ of pregnant women and increase maternal and fetal morbidity and mortality [3]. Furthermore, in the last years, the number of gestations in kidney diseases patients increased markedly. So, it is very important that renal function is closely monitored during pregnancy to prevent or minimize maternal and fetal complications.

Glomerular filtration rate (GFR) is considered to be the key marker of kidney function, critical for detection, evaluation and management of renal impairment [4]. However, the precise measurement of GFR is invasive, time consuming, expensive and technically difficult. More recently, calculation of estimated GFR (eGFR) using an empirical mathematical prediction formula based on single point endogenous serum markers have been encouraged as a simple, rapid and reliable means of assessing kidney function with varying degrees of success. These methods are generally accepted as a better 
tool for estimating renal function than serum creatinine alone. National and international organizations recommend that clinical laboratories report estimated GFR and that clinicians use estimated GFR to evaluate kidney function for all patients. [5] However, the guidelines specifically exclude interpretation in pregnant women in the absence of validation.

Serum creatinine has been pivotal for renal function evaluation because it is an inexpensive, common test in clinical practice. The factors associated with creatinine measure are well understood: Creatinine is derived from the metabolism of creatine in skeletal muscle and from dietary protein intake; it is released into the circulation at a relatively constant rate and has a stable plasma concentration. Creatinine is freely filtered across the glomerulus and is neither reabsorbed nor metabolized by the kidney. However, approximately 10 to 40 percent of urinary creatinine is derived from tubular secretion by the organic cation secretory pathways in the proximal tubule [6].

There are no fewer than 47 predictions equations currently available that use creatinine as endogenous marker of renal function, although the most common equations used to estimate renal function in adults are the Cockcroft-Gault $\left(\mathrm{CG}_{\mathrm{eq}}\right)$ and the simplified equation from the Modification of Diet in Renal Disease Study $\left(\mathrm{MDRD}_{\text {eq }}\right)$ [7]. These two equations differ in many aspects, including the predicted index (creatinine clearance for $\mathrm{CG}_{\mathrm{eq}}$ and $\mathrm{GFR}$ for $\mathrm{MDRD}_{\mathrm{eq}}$ ), units of predictions $\left(\mathrm{ml} / \mathrm{mim}\right.$ for $\mathrm{CG}_{\text {eq }}$ and $\mathrm{ml} / \mathrm{mim} / 1,73 \mathrm{~m}^{2}$ for $\mathrm{MDRD}_{\text {eq }}$ ) and variables used for the prediction (serum creatinine, gender, age and body weight for $\mathrm{CG}_{\mathrm{eq}}$ and serum creatinine , gender, age, and race for $\mathrm{MDRD}_{\mathrm{eq}}$ ) $[8,9]$.

Recently, other endogenous proteins easily measured in clinical laboratories have been suggested as better markers of GFR. Cystatin C, considered superior to creatinine in non pregnant women, has been recommended as an alternative and possibly superior marker in pregnancy. However, others factors such as diabetes, fat mass and inflammation may alter serum Cystatin $\mathrm{C}$ level and some reports have shown substantial variability in the relationship between GFR and Cystatin C among different populations [10], and more recent data seriously question its use in pregnant populations [11].

Inulin clearance may be considered the gold standard method to measure GFR in pregnancy, but it is costly, cumbersome and not practical outside a clinical research setting. The endogenous creatinine clearance $\left(\mathrm{C}_{\mathrm{cr}}\right)$, the primary tool to assess kidney function in non pregnant subjects, is equally useful in clinical practice for evaluating renal function during the gestational period. Clinicians caring for obstetrics patients are still waiting data if GFR estimating equations are accurate in pregnancy to use in clinical practice.

In the present study, we investigated the performance of $\mathrm{CG}_{\mathrm{eq}}$ and $\mathrm{MDRD}_{\mathrm{eq}}$ equations while using $\mathrm{ClCr}$ as the best approximation for GFR in healthy pregnant women. We aimed to analyse the performance of these estimating equations to predict renal function in pregnancy.

\section{MATERIALS AND METHODS}

One hundred sixty seven normal ambulatory pregnant women accepted to participate in the study that was conducted from January to December 2008 and renal function was contemporaneously estimated and calculated. All subjects were normotensive with no history of renal, cardiac, diabetic or vascular disease, and individuals having treatment with drugs affecting creatinine secretion were excluded. The normal pregnant women selected were between 20th and 30th weeks of gestation. All subjects gave written informed consent for creatinine clearance studies and the clinical research was approved by the local Human Research Ethics Committee.

Each pregnant woman on whom the study was carried out on an outpatient basis was carefully instructed in the collection of a 24 hour urine specimen. Blood samples were drawn at the morning before their usual morning meal when weight and height were obtained. They stayed on a free diet and on their normal physical activity. Creatinine was measured using a kinetic colourimetric assay (Jaffé method) on the same Roche Hitachi 917 equipment (Roche Diagnostic GmbH, Mannheim, Germany) and the assay was calibrated with an IDMS reference laboratory. Two samples were collected with interval of one week and the mean of the results was used to calculate renal function by creatinine clearance $\left(\mathrm{C}_{\mathrm{cr}}\right)$, Cockcroft-Gault equation $\left(\mathrm{CG}_{\mathrm{eq}}\right)$ and the simplified equation from the Modification of Diet in Renal Disease Study $\left(\mathrm{MDRD}_{\mathrm{eq}}\right)$.

$\mathrm{C}_{\mathrm{cr}}$ was calculated $(\mathrm{ml} / \mathrm{min})$ :

$\mathrm{C}_{\mathrm{cr}}=$ urinary creatinine $\mathrm{mg} / \mathrm{dl}$ X 24 hour urinary volume $\mathrm{ml} / \mathrm{min} /$ serum creatinine $\mathrm{mg} / \mathrm{dl}$

The prediction equations were calculated:

$\mathrm{CG}_{\text {eq }}(\mathrm{ml} / \mathrm{min})=140$ - age years $\mathrm{X}$ weight $_{\mathrm{kg}} / 72 \mathrm{X}$ serum creatinine $\mathrm{mg} / \mathrm{dl}$ with use of the 0,850 multiplier for female gender.

Simplified $\mathrm{MDRD}_{\mathrm{eq}}\left(\mathrm{ml} / \mathrm{min} / 1.73 \mathrm{~m}^{2}\right)=175$ [serum creatinine $\mathrm{mg} / \mathrm{dl} \quad \mathrm{X} \quad 0.011312]^{-1.154} \mathrm{X}$ Ageyears $^{-0.205} \mathrm{X}$ 0.742 .

To make allowance for comparison with Ccr, $\mathrm{MDRD}_{\mathrm{eq}}$ and CGeq results were adjusted for $1.73 \mathrm{~m}^{2}$ of body surface area (BSA) according to the formula:

$\operatorname{BSA}\left(\mathrm{m}^{2}\right)=0.007184 \mathrm{X}_{\text {height }}{ }_{\mathrm{cm}}^{0.725} \mathrm{X}$ weight ${ }_{\mathrm{kg}}^{0.425}$.

Statistical procedures included analysis of mean and SD for categorical and numerical data, analysis of $95 \%$ confidence intervals (95\%CIs) and analysis of variance (ANOVA) associated with Bonferroni multiple comparisons test. 


\section{RESULTS}

A total of 167 normal ambulatory pregnant women; mean age $32.06 \pm 5.04$ years were included in this study. Calculated creatinine clearance, $\mathrm{CG}_{\mathrm{eq}}$ and $\mathrm{MDRD}_{\mathrm{eq}}$

Table 1. Clinical and laboratorial data at the time of creatinine measurement.

\begin{tabular}{cl}
\hline Number of Pregnant women & \multicolumn{1}{c}{167} \\
\hline Age (year) & $32.06 \pm 5.04$ \\
Time of Pregnancy (week) & $25.08 \pm 3.03$ \\
Weight gain $(\mathrm{Kg})$ & $12.04 \pm 3.11$ \\
Serun creatinine $(\mathrm{mg} \%)$ & $0.59 \pm 0.12$ \\
Creatinine Clearance $\left(\mathrm{ml} / \mathrm{min} / 1.73 \mathrm{~m}^{2}\right)$ & $146.27 \pm 30.49$ \\
Cockcroft-Gault $_{\text {eq }}\left(\mathrm{ml} / \mathrm{min} / 1.73 \mathrm{~m}^{2}\right)$ & $168.41 \pm 38.80$ \\
MDRD $_{\text {eq }}\left(\mathrm{ml} / \mathrm{min} / 1.73 \mathrm{~m}^{2}\right)$ & $129.15 \pm 29.28$ \\
\hline
\end{tabular}

Table 2. Renal function $\left(\mathrm{ml} / \mathrm{min} / 1.73 \mathrm{~m}^{2}\right)$ measured by creatinine clearance $\left(\mathrm{C}_{\mathrm{cr}}\right)$, Cockcroft-Gault $\left(\mathrm{CG}_{\mathrm{eq}}\right)$ and $\mathrm{MDRD}_{\mathrm{eq}}$ and comparison among the measurements.

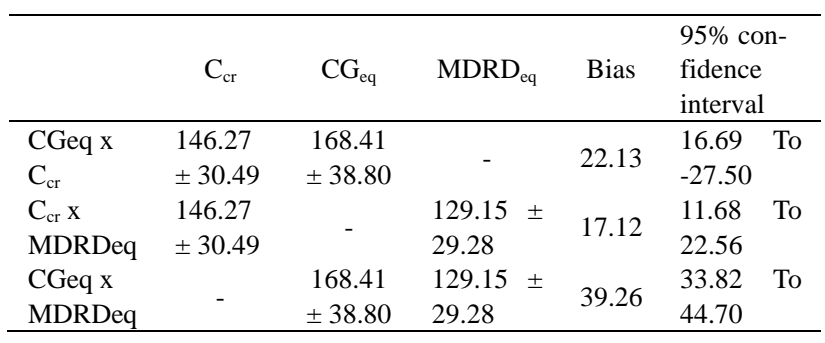

equations were performed from 20 to 29 weeks of pregnancy (25.80 \pm 3.03 weeks) and the weight gain during gestation until laboratory tests was $12.04 \pm 3.11 \mathrm{~kg}$. (Table 1).

The main analyses for indices of kidney function were with data normalized per $1.73 \mathrm{~m}^{2}$ and the results observed were $\mathrm{C}_{\mathrm{cr}}=146.27 \pm 30.49 \mathrm{ml} / \mathrm{min} / 1.73 \mathrm{~m}^{2}, \mathrm{CG}_{\mathrm{eq}}$ $=168.41 \pm 38.80 \mathrm{ml} / \mathrm{min} / 1.73 \mathrm{~m}^{2}, \mathrm{MDRD}_{\mathrm{eq}}=129.15 \pm$ $29.28 \mathrm{ml} / \mathrm{min} / 1.73 \mathrm{~m}^{2}$. (Figure 1).

When we compared calculated and estimated clearances for measurement of kidney function during pregnancy we observed that $\mathrm{CG}_{\mathrm{eq}}$ overestimated renal function $\left(168.41 \pm 38.80 \mathrm{ml} / \mathrm{min} / 1.73 \mathrm{~m}^{2}\right.$ and $146.27 \pm 30.49$ $\mathrm{ml} / \mathrm{min} / 1.73 \mathrm{~m}^{2}, \mathrm{CG}_{\text {eq }}$ versus Ccr respectively, $\mathrm{p}<0.001$ and the bias $22.13 \mathrm{ml} / \mathrm{min}$ ) and $\mathrm{MDRD}_{\text {eq }}$ underestimated renal function $\left(129.15 \pm 29.28 \mathrm{ml} / \mathrm{min} / 1.73 \mathrm{~m}^{2}\right.$ and $146.27 \pm 30.49 \mathrm{ml} / \mathrm{min} / 1.73 \mathrm{~m}^{2}, \mathrm{MDRD}_{\text {eq }}$ versus $\mathrm{Ccr}$ respectively, $\mathrm{p}<0.001$ and the bias $17,12 \mathrm{ml} / \mathrm{min}$ ). (Table 2, Figure 2 and Figure 3).

\section{DISCUSSION}

Effective renal plasma flow increase and Glomerular filtration rate change in pregnancy. GFR increase markedly during gestation, approximately $50 \%$ greater than non pregnant values during the second trimester, these high levels are maintained through gestational period until the 36th week, after which a decrease of $15 \%$ to $20 \%$ may occur (2). We studied kidney function of 167 normal ambulatory pregnant women from 20 to 29

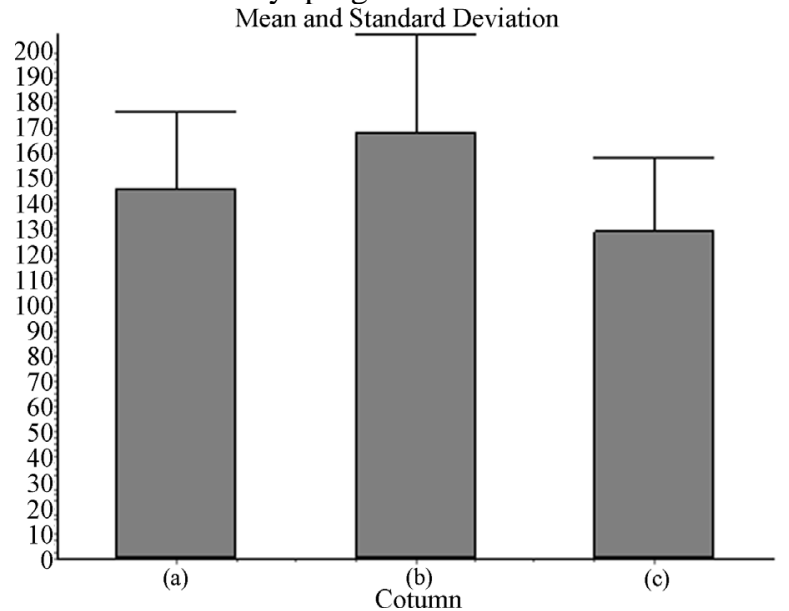

Figure 1. Renal function measured by creatinine clearance (a), Cockcroft-Gaulteq (b) and MDRDeq (c) during pregnancy.

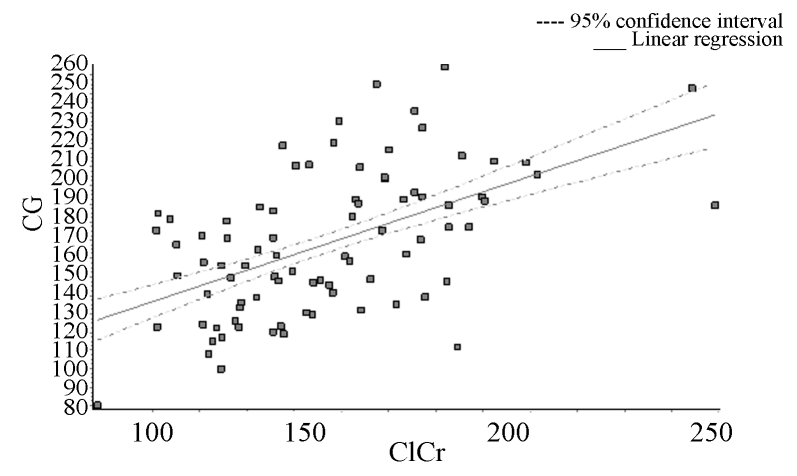

Figure 2. Poor correlation between renal function measured by Creatinine Clearance (ClCr) and Cockcroft-Gaulteq (CG) in normal pregnancy.

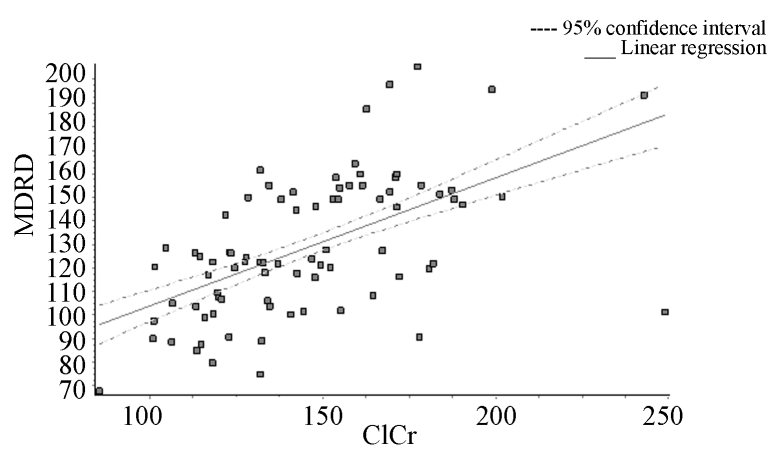

Figure 3. Poor correlation between renal function measured by Creatinine Clearance (ClCr) X MDRDeq in normal pregnancy.

weeks of pregnancy $(25.80 \pm 3.03$ weeks $)$, in the period 
of pregnancy where the renal function is more stable.

The Clearance of endogenous creatinine $\left(C_{c r}\right)$ was the best approximation of GFR in pregnancy to assess renal function in clinical practice. Because there is, at most, a small increase in the production and excretion of creatinine during normal gestation, the large increments in Ccr lead to reduction in its plasma level. Lower serum creatinine levels observed in pregnancy are a reflection of haemodilution due to the increase of plasma volume as well as hyperfiltration. Thus, values considered normal in nonpregnant women may reflect abnormal renal function in pregnancy [12].

Accurate GFR measurements using inulin infusion are impractical for large-scale application in pregnant population, while $\mathrm{C}_{\mathrm{cr}}$ is made complex by the need of obtaining accurate 24 hour urine collection. To minimize this last limitation we instructed women to take note of the start and end time of urine collection to allow for computation of the length of collection, and used the mean of two creatinine samples collected with interval of one week to calculate renal function. All the creatinine assays were performed in the same Technican AutoAnalyser to prevent the high inter-laboratory variations of creatinine [13] and the kidney function was contemporaneously estimated and calculated.

When we compared the results of estimating renal function using $\mathrm{CG}_{\mathrm{eq}}$ and $M D R D_{\text {eq }}$ equations with $\mathrm{C}_{\mathrm{cr}}$, we observed that $\mathrm{CG}_{\mathrm{eq}}$ overestimated (168.41 \pm 38.80 $\mathrm{ml} / \mathrm{min} / 1.73 \mathrm{~m}^{2}$ and $146.27 \pm 30.49 \mathrm{ml} / \mathrm{min} / 1.73 \mathrm{~m}^{2}, \mathrm{p}<$ 0.001 ) and $\mathrm{MDRD}_{\mathrm{eq}}$ underestimated renal function $\left(129.15 \pm 29.28 \mathrm{ml} / \mathrm{min} / 1.73 \mathrm{~m}^{2}\right.$ and $146.27 \pm 30.49$ $\mathrm{ml} / \mathrm{min} / 1.73 \mathrm{~m}^{2}$, $\mathrm{p}<0.001$ ), which demonstrated that $\mathrm{CG}_{\mathrm{eq}}$ and simplified $\mathrm{MDRD}_{\mathrm{eq}}$ equations are not useful measure of GFR in normal pregnancy to estimate renal function. Some studies have also demonstrated in normal, hypertensive and preeclamptic pregnancy, that both the $\mathrm{CG}_{\mathrm{eq}}$ and $\mathrm{MDRD}_{\mathrm{eq}}$ were also inaccurate in predicting kidney function when compared with $C_{c r}$ [14-16].

Bias (difference between measured $\left(\mathrm{C}_{\mathrm{cr}}\right)$ and estimated $\left(\mathrm{CG}_{\mathrm{eq}}\right.$ and $\left.\mathrm{MDRD}_{\mathrm{eq}}\right)$ kidney function) was used as a measure of performance. Bias of $\mathrm{CG}_{\text {eq }}$ prediction in pregnant women (22.13 from 16.69 to $27.57 \mathrm{ml} / \mathrm{min}$ ) may be explained by the rule that weight coefficients of the $\mathrm{CG}_{\mathrm{eq}}$ do not differentiate between muscular mass (relevant to creatinine generation) and non-muscular mass (not relevant to creatinine generation). Thus, the $\mathrm{CG}_{\mathrm{eq}}$ during gestation transforms any weight gain difference into a difference in predicted kidney function that tends to be overestimated in overweight. Generally in obstetric population, healthy women gain approximately $12.5 \mathrm{~kg}$ in the first pregnancy and $1 \mathrm{~kg}$ less in subsequent gestation and increase the body surface area. In our pregnant women group weight gain was $12.04 \pm$ $3.11 \mathrm{~kg}$ during gestation until laboratory tests to assess renal function and may have contributed to overestimated renal function by $\mathrm{CG}_{\text {eq. }}$. However, the correction of clearance results to $1.73 \mathrm{~m}^{2}$ of body surface area was not capable to correct this overestimated result [17].

In normal gestation, our results demonstrated that $\mathrm{MDRD}_{\text {eq }}$ underestimated renal function (Bias of 17.12 from 11.68 to $22.56 \mathrm{ml} / \mathrm{min}$ ) and is not useful measure in pregnant women on whom GFR increases markedly. Some large studies have recently concluded that using the $\mathrm{MDRD}_{\text {eq }}$ in healthy subjects is problematic. $\mathrm{MDRD}_{\mathrm{eq}}$ was derived from an adult population with chronic kidney disease most of whom had a GFR less than 60 $\mathrm{ml} / \mathrm{min} / 1.73 \mathrm{~m}^{2}$. Perhaps more important, GFR was systematically underestimated by $\mathrm{MDRD}_{\text {eq }}$ when GFR rises above $60 \mathrm{ml} / \mathrm{min} / 1.73 \mathrm{~m}^{2}$ in healthy subjects and clinical laboratory that estimate GFR by $\mathrm{MDRD}_{\mathrm{eq}}$ usually report the result as GFR $>60 \mathrm{ml} / \mathrm{min} / 1.73 \mathrm{~m}^{2}[18,19]$. Similarly in pregnancy, recent studies comparing $\mathrm{MDRD}_{\text {eq }}$ with inulin clearance in a small sample of healthy pregnant women have also demonstrated that $\mathrm{MDRD}_{\mathrm{eq}}$ underestimated GFR during gestation [20,21].

In conclusion: $\mathrm{CG}_{\mathrm{eq}}$ overestimated and $\mathrm{MDRD}_{\mathrm{eq}}$ underestimated significantly kidney function during gestation in healthy women and are not accurate enough to be used as screening tests to assess renal function in obstetric population. At present, 24-h urine collection for endogenous $\mathrm{C}_{\mathrm{cr}}$, and that may also be used for proteinuria measurement, remains as the best method to measure renal function during pregnancy in clinical practice, and there is no estimating equation that provides accurate eGFR during pregnancy. So, it is necessary to develop an accurate equation to pregnant women that considers the several important changes in maternal renal hemodynamics and provides an eGFR the most unbiased and precise as possible. Our results clearly demonstrated that $\mathrm{CG}_{\mathrm{eq}}$ and $\mathrm{MDRD}_{\text {eq }}$ cannot be recommended as a useful clinical tool in obstetric practice and clinicians caring for obstetric patients may soon see eGFR routinely reported alongside the traditional biochemistry.

\section{REFERENCES}

[1] Umans, J.A., Lindheimer, M.D. (1995) The renal adaptations to pregnancy is now nostalgic. Journal of Clinical Investigation, 96, 482-490. doi:10.1172/JCI118048

[2] Conrad, K. (2004) Mechanisms of renal vasodilation and hiperfiltration during pregnancy. Journal of the Society for Gynecologic Investigation, 7, 438-443. doi:10.1016/j.jsgi.2004.05.002

[3] ACOG practice bulletin. (2002) Diagnosis and management of preeclampsia and eclampsia. Obstetrics Gynecology, 99, 159-166.

[4] Levey, A.S., Eckardt, K.U., Tsukamoto, Y., et al. (2005) Definition and classification of chronic kidney disease (KDIGO). Kidney international, 67, 2089-2010. doi:10.1111/j.1523-1755.2005.00365.x 
[5] National Kidney disease education program: Information for health professionals (2004) National Institutes of Health, National Institutes of Diabetes and Digestive and Kidney Diseases, Bethesda, Maryland, USA.

[6] Shemesh, O., Golbetz, H., Kriss, J.P. and Myers, B.D. (1985) Limitations of creatinine as a filtration marker in glomerulopathic patients. Kidney Internation, 28, 830-838. doi:10.1038/ki.1985.205

[7] Johnson, D.W. (2005) Use of serum creatinine concentration to assess level of kidney function. Nephrology, 10, s133-s139. doi:10.1111/j.1440-1797.2005.00487 1.x

[8] Cockcroft, D.W., Gaul,t M.H. (1976) Prediction of creatinine clearance from serum creatinine. Nephron, 16, 31-41. doi:10.1159/000180580

[9] Levey, A.S., Green, T., Kusek, J.W., et al. (2000) A simplified equation to predict glomerular filtration rate from serum creatinine. Journal of the American Society Nephrology, 11, 151A.

[10] Stevens, L.A., Schmid, C.H., Greene, T., et al. (2009) Factors other than GFR affect serum cystatin levels. Kidney international, 75, 652-660. doi:10.1038/ki.2008.638

[11] Akbari, A., Lepage, N., Keely, E., Clark, H.D., Jaffey, M. and Filler, G. (2005) Cystatin C and beta trace protein as markers of renal function in pregnancy. British Journal of Obstetrics Gynecology, 112, 575-578. doi:10.1111/j.1471-0528.2004.00492.x

[12] Jeyabalan, A. and Conrad, K.P. (2007) Renal function during normal pregnancy and preeclampsia. Front Bioscience, 12, 2425-2437. doi:10.2741/2244

[13] Miller, W.G., Myers, G.L., Ashwood, E.R., et al. (2005) Creatinine measure: state of the art in accuracy and inter-laboratory harmonization. Archives Pathology \& Laboratory Medicine, 129, 297-304.

[14] Delemarre, F.M. and Schoenmakers, C.H. (2008) The MDRD formula in pregnancy. BJOG, 115, 1192.
[15] Marques, L.P.J., Rocco, R., Victor, M.H., Novaes, B.C., Carvalho, A.L.B. and Santos, O.R. (2009) Clinical using of estimating glomerular filtration rate equations during pregnancy. World Congress of Nephrology, Milan Italy, 22-26 May 2009, poster Su. 197.

[16] Côté, A.M., Lam, E.M., von Dadelszen, P., Mattman, A., Magee, L.A. (2010) Monitoring renal function in hypertensive pregnancy. Hypertens Pregnancy, 29, 318-29. doi:10.3109/10641950902968676

[17] Alper, A.B., Yi, Y., Webber, L.S., Pridjian, G., Mumeney, A.A., Saade, G., Morgan, J., Nuwayhid, B., Belfort, M. and Puschett, J. (2007) Estimation of glomerular filtration rate in preeclamptic patients. American Journal of Perinatology, 24, 569-574. doi:10.1055/s-2007-986697

[18] Geddes, C.C., Woo, M.Y. and Brady, S. (2008) Glomerular filtration rate - What is the rationale and justification of normalizing GFR for body surface area? Nephrol Dial Transplant, 23, 4-6. doi:10.1093/ndt/gfm662

[19] Stevens, L.A., Coresh, J., Deysher, A.E. and Levey, A.S. (2007) Evaluation of the MDRD study equation in a large diverse population. Journal of the American Society Nephrology, 18, 2749-2757. doi:10.1681/ASN.2007020199

[20] Froissart, M., Rossert, J., Jacquot, C., et al. (2005) Predictive performance of the MDRD and CockcroftGault equations for estimating renal function. Journal of the American Society Nephrology, 16, 763-773. doi:10.1681/ASN.2004070549

[21] Smith, M., Moran, P., Ward, M.K., Davison, J.M. (2008) Assessment of glomerular filtration rate during pregnancy using the MDRD formula. BJOG, 115, 109-112.

[22] Ahmed, S.B., Bentley-Lewis, R., Hollenberg, N.K., Graves, S.W., Seely, E.W. (2009) A comparison of prediction equations for estimating glomerular filtration rate in pregnancy. Hypertens Pregnancy, 28, 243-55. doi:10.1080/10641950801986720 